\title{
A Research Paradigm to Investigate Event-Related Shame and Guilt: Preliminary Findings
}

\author{
Jessica Grabow, Patricia Kulla and Joachim Kruse
}

Department for Clinical Psychology and Trauma Therapy, Bundeswehr University Munich

\begin{abstract}
Author Note
Jessica Grabow https://www.unibw.de/hum-psychologie/kpt/personen/grabow

Patricia Kulla https://www.unibw.de/hum-psychologie/kpt/kulla2

Joachim Kruse https://www.unibw.de/hum-psychologie/kpt/personen/kruse

We have no conflict of interest to disclose.

Correspondence concerning this article should be addressed to Jessica Grabow, Bundeswehr University Munich, Werner-Heisenberg-Weg 39, 85577 Neubiberg. Email: jessica.grabow@unibw.de
\end{abstract}




\begin{abstract}
Objective: Recent findings suggest an advantage of Imagery Rescripting and Reprocessing Therapy (IRRT) over Prolonged Exposure (PE) for non-fear emotions in PTSD. Still, results are inconsistent and mechanisms of change unclear. Our broader aim is to study effects of different psychotherapeutic treatment components on event-related emotions and psychological symptoms. In this pilot study, we wanted to evaluate if our audiotaped memory retrieval task (MRT) is able to elicit event-related emotions. Second, we compared effects of two standardized mini-interventions based on IRRT and PE on event-related shame and guilt, general distress and affective state.

Method: Forty-four healthy participants received instructions via headphone to imagine a biographic event where they felt shame and/or guilt (MRT) and to re-experience and reprocess (IR) the event or to re-experience it twice (PE). The control group listened to a neutral informational text $(\mathrm{Cl})$. Outcome measures were general distress (SUD), positive and negative affect as well as event-related shame and guilt via self-report.
\end{abstract}

Results: We found significant increase of negative affect and decrease of positive affect after MRT. Somewhat contrary to our hypotheses, negative affect decreased significantly not only after IR but also after $\mathrm{Cl}$ and not after PE. Only after IR, positive affect increased almost significantly. For eventrelated shame and guilt, no group differences were found.

Conclusions: Our audio instructions modified event-related emotions partly in the expected directions. Our results are consistent with previously reported higher acceptance of IR compared to PE. However, shortcomings in the experimental and sampling procedure do not allow for further conclusions. 
Clinical Impact Statement: We propose a new research paradigm of high standardization, easy application and replicability to investigate psychological trauma, differential effects of therapy components and mechanism of change in nonclinical samples. It may add to the understanding of processes in trauma therapy and help therapists choose between treatment options. Our study gives preliminary evidence for the additional value of IR interventions to PE in terms of acceptance and effectiveness. In addition, our paradigm might be useful as an online therapy tool for treating effects of aversive life-events.

Keywords: Experimental Psychopathology, Trauma, Shame \& Guilt, Non-Fear Emotions, Trauma-Related Emotions 


\section{A Research Paradigm to Investigate Event-Related Shame and Guilt: Preliminary Findings}

A vast body of research states that a combination of cognitive and behaviour therapy such as Prolonged Exposure (PE), Cognitive Processing Therapy (CPT), Cognitive Behaviour Therapy with trauma focus (CBT-T), or Eye Movement Desensitization and Reprocessing Therapy (EMDR) are effective in treating PTSD (Bradley et al., 2005; C. Lewis, Roberts, Andrew, et al., 2020; Watkins et al., 2018). However, there are non-responders and we still lack a thorough understanding of factors that determine these subgroup (C. Lewis, Roberts, Gibson, \& Bisson, 2020). One approach is to investigate trauma-related emotions. Classic PTSD models (Ehlers \& Clark, 2000; Foa \& Kozak, 1986) outline a fearbased disorder and standard cognitive-behavioural treatments consequently focus on altering pathological fear structures (Watkins et al., 2018). However, non-fear emotions such as shame, guilt, disgust, and anger seem to play an important role in the onset and course of PTSD psychopathology (Badour \& Feldner, 2018; Bomyea \& Allard, 2017; Feiring \& Taska, 2005; Freed \& D'Andrea, 2015; Kubany \& Watson, 2003). Saraiya and Lopez-Castro (2016) conclude in a review about the role of shame in PTSD that addressing shame in the course of the treatment might be "fundamental to recovery" (S. 169); the same applies to guilt cognitions (Pugh et al., 2015). Interestingly, habituation as a psychophysiological customization process as the key working mechanism of exposure seems to be less effective for guilt and shame compared to fear. In a study by Harned et al. (2015) who measured within- and between-session changes of several trauma-related emotions and general distress, only fear and distress decreased within one session. However, they still observed reductions in shame, guilt and disgust between sessions indicating that other mechanisms yield the effect.

Both shame and guilt encompass a negative evaluation of oneself. Following the distinction made by H. B. Lewis (1971), shame refers to the whole self, which is considered as wrong and deficient, whereas guilt involves a negative evaluation of ones behaviour or actions. Creating self-compassion is a key element in therapy when guilt or shame are involved (Au et al., 2017). Imagery Rescripting and Reprocessing Therapy (IRRT, Schmucker \& Köster, 2017) provides an interesting method for this. A typical IRRT-session starts with an exposure phase similar to PE (Foa et al., 2014) but continues with rescripting the scene. At first, the patient imagines how the present-day self enters the scene and 
masters or resolves the situation in a way that the former, traumatized self can no longer be harmed (e.g. police comes and captures the perpetrator). In a second phase, the therapist guides the presentday self to offer compassion and comfort to the former self (Schmucker \& Köster, 2017).

There are some clinical trials, which suggest an advantage of IRRT compared to PE in changing non-fear trauma-related emotions (Arntz et al., 2007; Grunert et al., 2007). However, two studies by Langkaas et al. (2017) and Øktedalen et al. (2015) were not able to confirm these findings. On a slightly different notion, Arntz et al. (2007) found a considerably lower dropout rate in the group with imagery rescripting (25\% dropout) than without (51\% dropout). In several clinical and analogue studies participants and therapists reported that IRRT was less distressing compared to mere exposure (Hagenaars \& Arntz, 2012; Kunze et al., 2017; Siegesleitner et al., 2019). In sum, IRRT seems a promising addition to standard PTSD treatments when event-related shame and guilt are present but several questions remain open.

Analogue studies have proven a useful and economic means to study underlying mechanisms and effects of discrete treatment components (Waters et al., 2017). In PTSD research, the trauma film paradigm (TFP, Holmes \& Bourne, 2008) has been widely used as an analogue (e.g. Hagenaars \& Arntz, 2012; Kunze et al., 2015). The traumatic memory is being created for the experiment by watching a highly disturbing film scene. So far, findings provide evidence for IRRT and PE as an effective preventive tool for the onset of PTSD-related subclinical symptoms. Siegesleitner et al. (2019) presented a multiple-day TFP to investigate therapeutic effects. Still, the personal impact of an aversive film compared to a biographic event on self-concept and affect is limited. Strohm et al. (2019) and Çili et al. (2017) chose to work with memories of distressing biographic events and observed changes in event-related emotion, intrusive memories and self-esteem through one session of IRRT (using a protocol from Arntz \& Weertman, 1999). To activate the memory of the distressing event, participants were asked to describe the aversive event to the experimenter who helped by asking stimulating questions.

We generally followed the procedure of Strohm et al. (2019) and Çili et al. (2017) instructing participants to choose memories of distressing interpersonal events that are associated with shame 
and guilt. In order to facilitate standardization, administration and replicability of the study, we recorded audio instructions for memory retrieval and intervention phases.

The aim of this pilot study was twofold. First, we wanted to evaluate if our audiotaped memory retrieval task (MRT) is at all able to elicit event-related emotions, specifically shame and guilt, in a healthy sample. Second, we wanted to compare two mini-interventions based on IR and PE to a nontherapeutic control intervention $(\mathrm{Cl})$ hypothesizing that $\mathrm{IR}$ would outperform $\mathrm{PE}$ and both interventions would outperform $\mathrm{Cl}$ in reducing event-related shame and guilt and other event-related emotions.

\section{Method}

\section{Participants}

Fifty-six students of the Bundeswehr University Munich, Germany, completed online assessment on day 1 . Five participants were excluded from further participation due to mental health problems. However, two ignored the instructions and completed all questionnaires. Our screening procedure consisted of 26 questions covering all relevant sections of ICD-10 chapter F and two questions assessing current daily functioning and mental stress. None reported suicidal thoughts, selfinjury, or PTSD assessed with the German version of the Impact of Events Scale - revised (IES-R, Maercker \& Schützwohl, 1998; Weiss \& Marmar, 1996). Three participants dropped out after day 1 $(4,6 \%)$, another five after day $2(8,1 \%)$. Two participants completed the online assessments in the wrong order. Thus, the total sample at day 2 (at the lab) consisted of $n=48$ participants with $n_{\mathbb{R}}=17$, $n_{P E}=16$ and $n_{C I}=15$. For analysis over all three days, sample size was $n=41$ with $n_{\mathbb{R}}=15, n_{P E}=13$ and $\mathrm{n}_{\mathrm{Cl}}=13$.

There was a significantly unequal distribution of gender to treatment condition $\left(X^{2}(2)=6.43\right.$, $\mathrm{p}<0.05)$ with considerably more male participants in IR (82.4\%) than in $\mathrm{Cl}(40.0 \%)$. Participants' characteristics and information about the biographic events for the complete sample as well as for each treatment group are displayed in table 1. 
Table 1.

Sample characteristics at baseline.

\begin{tabular}{|c|c|c|c|c|c|}
\hline & $\begin{array}{l}\text { All } \\
(n=48)\end{array}$ & $\begin{array}{l}\text { IR } \\
(n=17)\end{array}$ & $\begin{array}{l}P E \\
(n=16)\end{array}$ & $\begin{array}{l}\mathrm{Cl} \\
(\mathrm{n}=15)\end{array}$ & $\begin{array}{l}\text { Comparison be- } \\
\text { tween conditions }\end{array}$ \\
\hline \multicolumn{6}{|l|}{ Gender: } \\
\hline n female/male & $17 / 31$ & $3 / 14$ & $5 / 11$ & $9 / 6$ & $X^{2}(2)=6.43^{*}$ \\
\hline$\%$ female/male & $35.4 / 64.4$ & $17.6 / 82.4$ & $31.3 / 68.8$ & $60.0 / 40.0$ & \\
\hline \multicolumn{6}{|l|}{ Age in years: } \\
\hline$M(S D)$ & $22.73(2.52)$ & $22.88(2.69)$ & $22.56(2.78)$ & $22.73(2.15)$ & $\mathrm{F}(2,45)=0.06, \mathrm{~ns}$ \\
\hline \multicolumn{6}{|l|}{$\begin{array}{l}\text { Categories of shameful } \\
\text { event: } n(\%)\end{array}$} \\
\hline Humiliation & $18(37.5 \%)$ & $5(29.4 \%)$ & $5(31.3 \%)$ & $8(53.3 \%)$ & \\
\hline Mobbing & 12 (25.0\%) & 5 (29.4\%) & $4(25.0 \%)$ & $3(20.0 \%)$ & \\
\hline $\begin{array}{l}\text { Rejection by loved } \\
\text { one }\end{array}$ & 5 (10.4\%) & 2 (11.8\%) & 2 (12.5\%) & $1(6.7 \%)$ & \\
\hline $\begin{array}{l}\text { Harmed by family } \\
\text { member }\end{array}$ & $4(8.3 \%)$ & 2 (11.8\%) & $1(6.3 \%)$ & $1(6.7 \%)$ & \\
\hline Abuse by parent & $3(6.3 \%)$ & 2 (11.8\%) & 1 (6.3\%) & $0(0.0 \%)$ & \\
\hline Other & 4 (8.3\%) & $1(5.9 \%)$ & $1(6.3 \%)$ & $2(13.3 \%)$ & \\
\hline Missing & $2(4.2 \%)$ & $0(0.0 \%)$ & 2 (12.5\%) & $0(0.0 \%)$ & \\
\hline \multicolumn{6}{|l|}{ Age at event in years: } \\
\hline$M(S D)$ & $13.51(4.61)$ & $13.79(4.46)$ & $13.07(5.18)$ & $13.60(4.52)$ & $F(2,43)=0.09, n s$ \\
\hline
\end{tabular}

\section{Procedure}

The project was accepted by the ethics committee of the Bundeswehr University Munich. Participants completed the screening questions and baseline-assessment at home (see figure 1 for detailed procedure and measurements). The following day, participants came to our campus lab. Seated in single, soundproof PC booths, they received audio instructions via headphones to activate memories of a previously chosen autobiographic event laden with shame and guilt. There should be at least one perpetrator to resemble an interpersonal trauma situation (memory retrieval task, MRT). Several questions stimulated the recall of sensory information (e.g. "What do you see when you look around? What can you hear?") to ensure a vivid imagination of the scene. Then, they were randomly assigned to one of three conditions: imagery rescripting (IR), prolonged exposure (PE), or control intervention (CI). During PE (based on Foa et al., 2014) we instructed participants to re-experience the situation twice by verbally describing the course of events. During IR (based on Schmucker \& Köster, 2017) participants were told to re-experience it once and then imagine that the present-day self strikes back at the perpetrator and shows compassion towards the younger self. Participants in 


\section{Figure 1.}

Procedure with Measures at Days 1, 2, and 3.

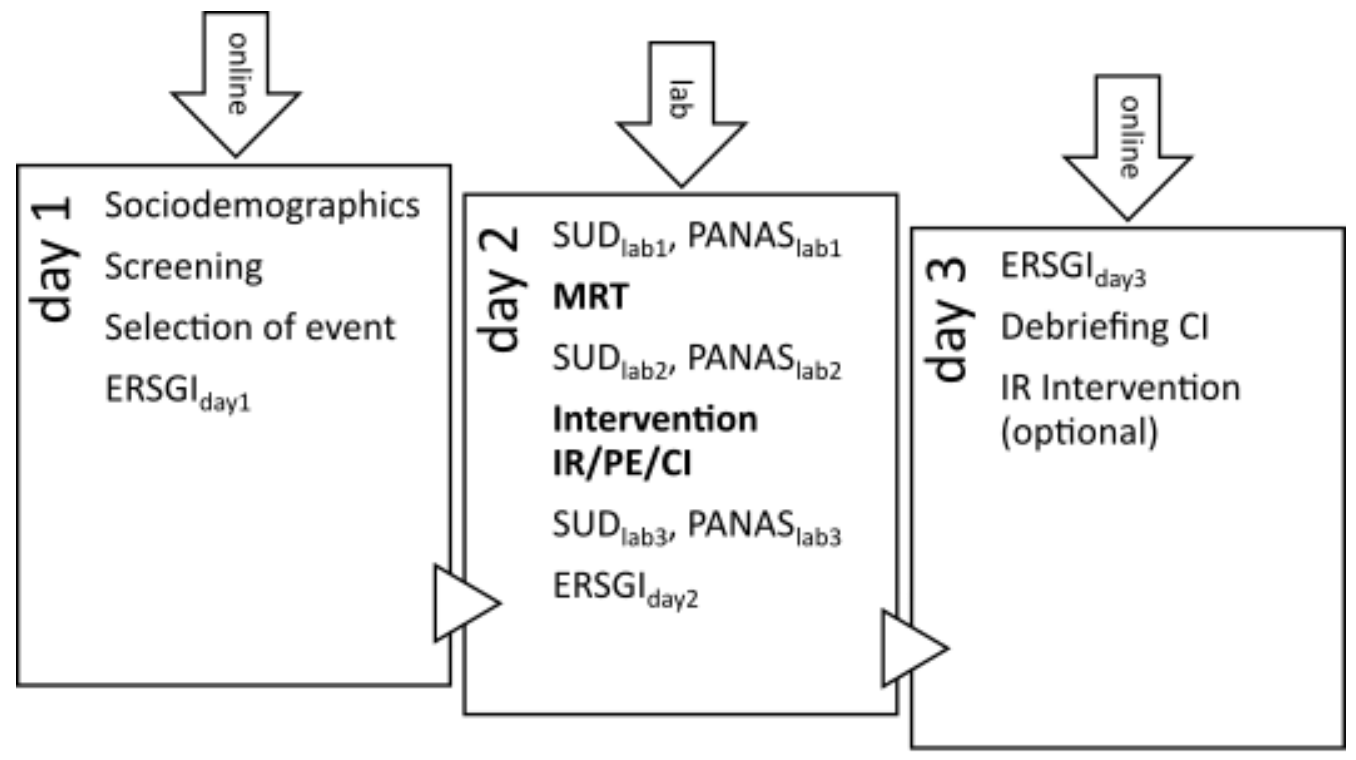

Note. Online = participants completed questionnaires at home, lab = participants completed questionnaires at campus laboratory; ERSGI = Event-Related Shame and Guilt Inventory; SUD = Subjective Units of Distress; PANAS = Positive and Negative Affect Schedule; IR = Imagery Rescripting; $\mathrm{PE}=$ Prolonged Exposure; $\mathrm{Cl}=$ Control Intervention .

the control condition listened to an informational text about amber (based on an article from

Wikipedia). On the following day, participants completed post-assessment. $\mathrm{Cl}$ was debriefed and offered IR treatment.

\section{Measures}

\section{Event-related shame and guilt}

As there is no questionnaire to assess event-related shame and guilt in German language we developed the Event-related Shame and Guilt Inventory (FESS, Kulla, Grabow, Bleiziffer, Kratzer, \& Kruse, in prep.) building upon existing English questionnaires like the Trauma-related Guilt Inventory (Kubany et al., 1996), the Trauma Related Shame Inventory ( $\varnothing$ ktedalen et al., 2014) and the HIV and Abuse Related Shame Inventory (Neufeld et al., 2012).

All emotion ratings referred to the biographic event. Main outcome measure was a 40 -items version of our recently developed Event-related Shame and Guilt Inventory (ERSGI, Kulla et al., 2021). For reasons of factorial validity, we used the revised version with six items for shame and guilt 
respectively. Internal consistency was good to excellent with Cronbach's $\alpha$ of .84 (guilt) and .90 (shame) in the present sample at day 2.

\section{Emotional activation}

To track arousal and affective state throughout memory retrieval and treatment administration during the laboratory session, we used the German version of the Positive and Negative Affect Schedule (PANAS, Breyer \& Bluemke, 2016; Watson et al., 1988) calculating separate scores for negative affect (NA) and positive affect (PA). Also, participants rated their arousal in subjective units of distress (SUD), both on a visual analogue scale.

\section{Statistical Analysis}

We used SPSS 25 and RStudio for all analyses. In preliminary analyses, we checked for outliers and distribution parameters. There was missing data at day 1 as two participants had been discarded after the screening procedure but returned for days 2 and 3 . Analyses of assumptions showed that homogeneity of covariances assessed with Box's test was given except for NA. Homogeneity of error variances assessed by Levene's test was partly violated (NA at lab3, PA at lab1) and for between-group analyses for SUD and NA. As skewness and kurtosis did not exceed normal ranges, we tested parametrically assuming robustness of ANOVA (Arnau et al., 2013). We performed separate ANOVAs for SUD, PA, and NA, as well as event-related shame and guilt with factors time (lab1-lab3 resp. days 1-3) and condition. Post-hoc tests were performed to detect changes through memory retrieval task and intervention respectively and univariate ANOVAs as well as contrast analysis to detect group differences at lab1/day 1 and lab3/day 3 reporting Greenhouse-Geisser values where needed. We calculated effect sizes for all outcome variables using Cohen's d correcting for dependency (Morris \& DeShon, 2002) and different sample sizes (Hedges' g, Lakens, 2013).

\section{Results}

\section{Effects of memory retrieval task}

Means and standard deviations for our main outcome variables at all time levels are displayed in table 2. We found significant main effects of time for SUD, NA, and PA. Effect sizes were large (each 
$d>1.26,95 \%$-Cis [0.83-1.85]). No main effects for group and no interactions revealed for lab1 to lab2, each $F(2,45)<0.92$ and $p>0.41$.

Table 2.

Mean scores and standard deviations of outcome measures over time

\begin{tabular}{llllllllll}
\hline & lab1 & & \multicolumn{9}{c}{ lab2 } & & lab3 & & \\
& $\mathrm{IR}$ & $\mathrm{PE}$ & $\mathrm{Cl}$ & $\mathrm{IR}$ & $\mathrm{PE}$ & $\mathrm{Cl}$ & $\mathrm{IR}$ & $\mathrm{PE}$ & $\mathrm{Cl}$ \\
\hline SUD & 17.65 & 14.38 & 18.13 & 32.18 & 35.88 & 41.27 & 22.82 & 44.94 & 20.20 \\
$M(S D)$ & $(18.61)$ & $(16.21)$ & $(23.10)$ & $(24.05)$ & $(24.25)$ & $(30.08)$ & $(20.33)$ & $(31.97)$ & $(21.07)$ \\
PANAS & & & & & & & & & \\
Negative & 10.79 & 11.87 & 12.79 & 22.54 & 25.53 & 28.08 & 15.25 & 27.96 & 13.09 \\
$M(S D)$ & $(11.05)$ & $(17.25)$ & $(12.74)$ & $(17.74)$ & $(18.88)$ & $(21.53)$ & $(15.25)$ & $(23.85)$ & $(14.75)$ \\
Positive & 51.40 & 55.16 & 49.85 & 40.57 & 41.92 & 36.19 & 48.15 & 42.66 & 36.49 \\
$M(S D)$ & $(17.35)$ & $(12.35)$ & $(11.16)$ & $(21.01)$ & $(13.85)$ & $(12.36)$ & $(20.05)$ & $(19.99)$ & $(9.90)$ \\
ERSGI & day 1 & & & day 2 & & & day 3 & & \\
Shame & 4.67 & 2.31 & 5.77 & 5.67 & 2.69 & 7.38 & 5.07 & 1.92 & 5.23 \\
$M(S D)$ & $(4.47)$ & $(3.52)$ & $(5.13)$ & $(5.15)$ & $(3.73)$ & $(6.69)$ & $(5.28)$ & $(3.55)$ & $(4.82)$ \\
Guilt & 4.87 & 3.62 & 6.85 & 4.73 & 3.62 & 8.00 & 4.20 & 3.62 & 5.15 \\
$M(S D)$ & $(5.13)$ & $(4.11)$ & $(6.05)$ & $(4.08)$ & $(3.82)$ & $(6.31)$ & $(4.25)$ & $(3.86)$ & $(5.51)$ \\
\hline
\end{tabular}

Note. SUD = Subjective Units of Distress; PANAS = Positive and Negative Affect Schedule; ERSGI = EventRelated Shame and Guilt Inventory; IR = Imagery Rescripting; PE = Prolonged exposure; $\mathrm{Cl}=$ Control Intervention; lab1-3 were all measured at day2: lab1 = before memory retrieval, lab2 = after memory retrieval, lab3 = after intervention; ERSGI at day2 was measured after memory retrieval and intervention;

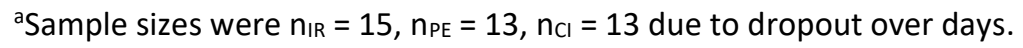

\section{Treatment effects on distress and positive/negative affect}

For SUD, post-hoc tests showed a significant decrease from lab2 to lab3 $(F(1,45)=6.35, p<$ $0.05, d=-0.31,95 \%-\mathrm{Cl}[-0.71 ; 0.093])$. We found a significant time $x$ condition interaction $(F(4,90)=$ $6.21, p<0.01$ ) with post-hoc tests showing that this was due to a significant interaction from lab2 to lab3 $(F(2,45)=9.41, p<0.01)$. Single analysis showed that there was a significant decrease of SUD in $\mathrm{Cl}(\mathrm{F}(1,14)=37.38, \mathrm{p}<0.01, \mathrm{~d}=-1.80,95 \%-\mathrm{Cl}[-2.64 ;-0.95])$ whereas SUD increased marginally significantly in PE $(F(1,15)=3.44, p=0.08, d=0.79,95 \%-C l[-0.13 ; 1.29])$. Between group analyses revealed a significant main effect for group at lab3 when controlling for lab1 $(F(2,44)=7.42, p<0.01)$ with contrast analysis showing that this was due to significantly higher SUD-values in PE compared to $\operatorname{IR}(p<0.01, \mathrm{~g}=0.83,95 \%-\mathrm{Cl}[0.12 ; 1.54])$ and $\mathrm{Cl}(p<0.01, \mathrm{~g}=0.91,95 \%-\mathrm{Cl}[0.17 ; 1.65])$. Changes in distress, negative and positive affect are displayed in figure 2. 


\section{Figure 2.}

Distress, Negative and Positive Affect before Memory Retrieval, after Memory Retrieval and after Intervention.
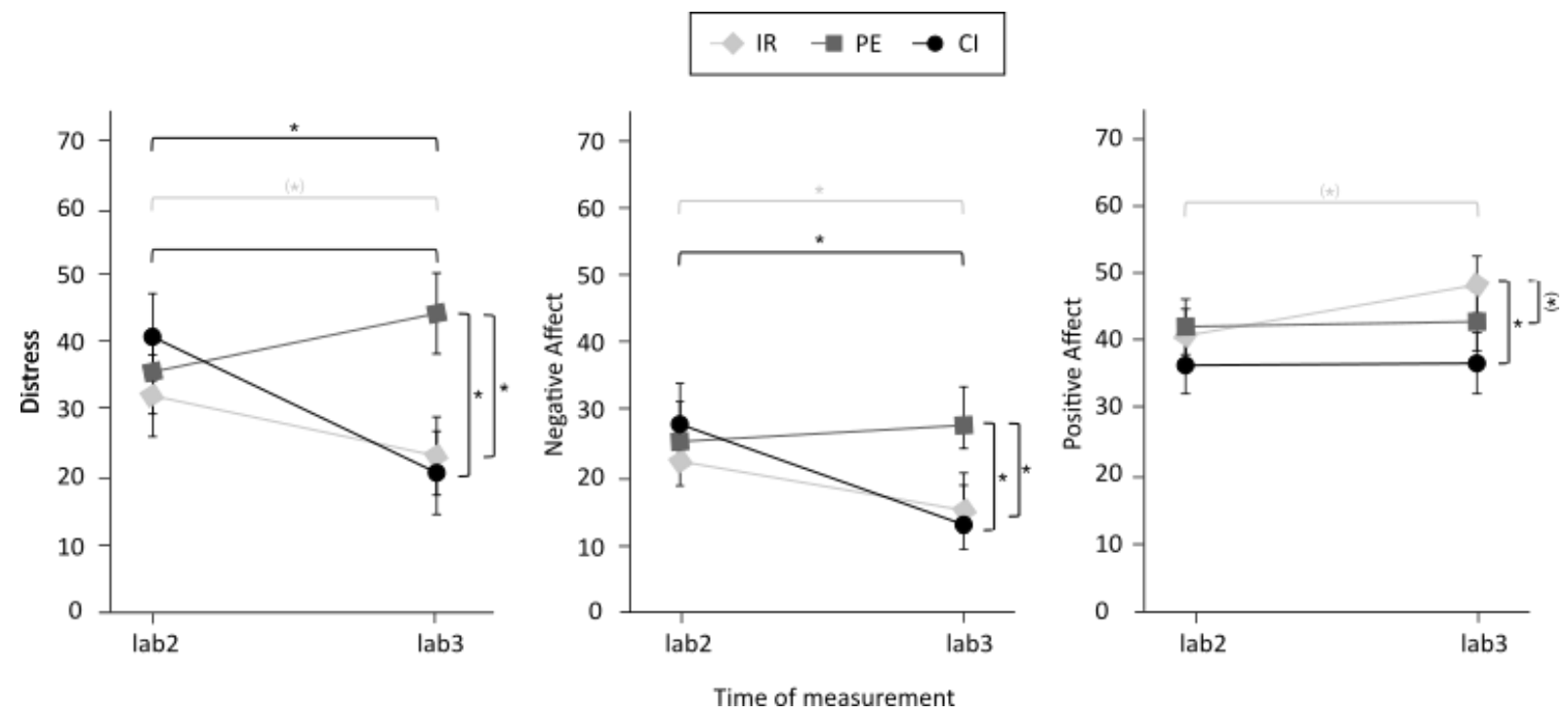

Note. Range of values from 0 to $100 ; \mathrm{IR}=$ Imagery Rescripting; $\mathrm{PE}=$ Prolonged Exposure; $\mathrm{Cl}=$ Control Intervention; ${ }^{*}=p$-value $<0.05 ;\left({ }^{*}\right)=p$-value $<0.10 ;$ lab2 = after memory retrieval, lab3 = after intervention; highest square brackets indicate main effects.

For NA, post-hoc tests showed a significant decrease from lab2 to lab3 $(F(1,45)=12.42, p<$ $0.01, d=-0.46,95 \%-\mathrm{Cl}[-0.87 ;-0.06])$. We also found a significant time $\mathrm{x}$ condition inter-action $(\mathrm{F}(4,90)$ $=4.01, \mathrm{p}<0.01$ ) with post-hoc tests showing that this was due to a significant interaction from lab2 to $\operatorname{lab3}(F(2,40)=7.06, p<0.01)$. Single analysis showed a significant decrease of $\operatorname{IR}(F(1,40)=7.05, p<$ $0.01, d=-0.61,95 \%-\mathrm{Cl}[-1.30 ; 0.08])$ and $\mathrm{Cl}(\mathrm{F}(1,40)=33.16, \mathrm{p}<0.01, \mathrm{~d}=-1.66,95 \%-\mathrm{Cl}[-2.49 ;-0.83])$. There was no main effect of group. However, single between group analyses revealed significant differences at lab3 when controlling for lab1 $(F(2,44)=4.92, p=.01)$ with contrast analyses showing that this was due to significantly higher NA-values in $\mathrm{PE}$ compared to $\mathrm{Cl}(\mathrm{p}<0.01, \mathrm{~g}=0.74,95 \%-\mathrm{Cl}$ $[0.02 ; 1.47])$ and $\mathrm{IR}(\mathrm{p}=0.03), \mathrm{g}=0.64,95 \%-\mathrm{Cl}[-0.06 ; 1.34])$.

For PA, post-hoc test showed no significant change for lab2 to lab3 over all groups. Only in IR, there was a marginally significant increase of PA from lab2 to lab3 $(F(1,16)=4.37, p=0.05, d=0.50$, $95 \%-\mathrm{Cl}[-0.19 ; 1.18])$. No significant main effect of group or interaction revealed. However, single between group analyses revealed a marginally significant difference at lab3 when controlling for lab1 $(F(2,44)=2.67, p=.08)$ with contrast analysis showing that this was due to (marginally) significantly 
higher PA-values in IR compared to $\mathrm{Cl}(p<0.05, \mathrm{~g}=0.73,95 \%-\mathrm{Cl}[0.01 ; 1.44])$ and $\mathrm{PE}(\mathrm{p}=0.08, \mathrm{~g}=0.27$, $95 \%-\mathrm{Cl}[-0.41 ; 0.96])$.

\section{Treatment effects on event-related shame and guilt}

For shame, we found a significant main effect of time $(F(2,76)=5.48, p<0.01)$. Post-hoc tests showed significant change in shame both from day 1 to day $2(F(1,38)=7.91, p<0.01, d=0.45,95 \%$ $\mathrm{Cl}[0.04 ; 0.87])$ as well as from day 2 to day $3(F(1,38)=9.92, p<0.01, d=-0.49,95 \%-\mathrm{Cl}[-0.92 ;-0.06])$. No significant main effect of group and no significant interactions were found. Also, single between group analyses revealed no significant differences at day 3.

For guilt, there was a significant main effect for time $(F(2,60.67)=5.53, p<0.05)$. Post-hoc tests showed that this was due to a significant change in guilt from day 2 to day $3(F(1,38)=12.19, p$ $<0.01, d=-0.49,95 \%-\mathrm{Cl}[-0.91 ;-0.06])$. Overall, there was no significant interaction, but post-hoc tests revealed a significant interaction of time and condition for day 2 to day $3(F(2,38)=7.08, p<0.01)$. However, this was only due to a significant change in $\mathrm{Cl}(\mathrm{F}(1,12)=12.43, \mathrm{p}<0.01, \mathrm{~d}=-0.37,95 \%-\mathrm{Cl}[-$ $1.05 ; 0.31])$ while treatment groups remained relatively stable. Single between group analyses revealed no significant differences at day 3 .

\section{Discussion}

The purpose of the present study was to evaluate the usefulness of an alternative PTSD analogue design to study treatment effects on the event-related non-fear emotions shame and guilt. Therefore, we instructed participants via headphones to imagine a biographic event where they felt guilt and/or shame (MRT) and exposed them to one of two imagery mini-treatments (IR and PE) or a control intervention $(\mathrm{Cl})$ while tracking arousal and affective state. The following day, we repeated assessment of event-related shame and guilt.

Our first aim was to examine whether our audio-delivered MRT is able to activate eventrelated emotion. This hypothesis was confirmed: SUD and NA scores were significantly higher after MRT while PA decreased significantly. However, as there was no control group we cannot rule out that the effect emerged by chance. We mean to address this in further studies. 
Our second aim was to replicate findings from other analogue and clinical studies, which tried to examine treatment effects and mechanisms of change in IRRT and PE (Çili et al., 2017; Grunert et al., 2007; Hagenaars \& Arntz, 2012; Kunze et al., 2017). Our hypotheses were only partly confirmed. We expected SUD and NA to decrease after both interventions. That was only true for IR but not for PE. Furthermore and contrary to our expectations, SUD and NA also decreased after $\mathrm{Cl}$, so that after the intervention phase, $\mathrm{Cl}$ and IR showed significantly lower SUD and NA values than PE. Interestingly, in a study using the trauma film paradigm of Dibbets and Arntz (2016) participants in the control condition (reading a magazine) also reported lowest levels of distress (SUD) compared to imagery rescripting and exposure interventions. Some participants in the control condition pointed out to the experimenter that they found the information about amber very interesting suggesting that some form of distraction took place. Distraction is a strategy of avoidance, which effectively reduces emotions and arousal in the short term. If this was the case, effects should reveal in the expected directions at a later point of time. Unfortunately, we did not collect PANAS and SUD data on day 3.

In line with our expectations, PA was marginally higher after IR but not after $\mathrm{Cl}$ and PE. However, the effect was only visibly by trend and needs further confirmation. It still adds to findings that IR seems to be less distressing than PE (Siegesleitner et al., 2019). However, participants needed merely half the amount of time to complete PE $(4.58 \mathrm{~min})$ compared to IR $(9.26 \mathrm{~min})$ which might have prevented effective habituation to evolve. In further studies, we will take care that both interventions are similar in length.

Scores of our newly developed Event-related Shame and Guilt Inventory (FESS) were higher on day 2 compared to day 1 . This contradicted our expectations, as on day 2 the data was collected after the intervention phase. However, on day 1 no memory retrieval took place before administering the FESS, which might explain why event-related shame and guilt were low. On day 3 , shame and guilt scores were lower compared to day 2. However, this was mainly due to an unexpected strong decrease of $\mathrm{Cl}$, but no between group effects evolved. We also planned to investigate into mechanisms of change building upon Kunze et al. (2019). But, as Cl outperformed IR and PE for event-related shame 
and guilt, requirements for the mediation analysis were lacking. We intend to address this aim in future studies.

The strongest limitation of the current study arises from the small sample size and unbalanced gender distribution over intervention groups. When computing an ANOVA with factors time (days 13) and sex we found a significant interaction suggesting that our memory retrieval task activated considerably more feelings of event-related guilt in female participants than in male $(F(1,44)=5.45, p$ $<0.05)$. For shame, we observed the same tendency. While this finding is not unexpected as women generally experience more shame and guilt compared to men (Kocherscheidt et al., 2002; Kubany et al., 1996) it might have caused a strong floor effect of the MRT in the treatment groups (predominantly male) obscuring possible effects of any subsequent intervention. Additionally, the clinical nature of the FESS, which explicitly taps into maladaptive feelings, might have limited variance and the manifestation of effects in our healthy sample. Another limitations stems from the preliminary nature of the FESS. Alternatively, we could have worked towards a translation of established inventories like the TRSI or the TRGI. We decided to develop a new instrument that works with the distinction between shame and guilt that was proposed by H. B. Lewis (1971) and is shorter in length compared to existing questionnaires in English language. However, we do not know yet if the ERSGI is sufficiently valid and sensitive for change.

The instruction of the MRT was supposed to activate events associated with maladaptive shame and guilt. However, while descriptions of events showed that participants chose indeed typical shame-laden events in which they were humiliated or painfully exposed, PANAS items "ashamed" and "guilty" were by no means rated highest but "upset" and "distressed". This might also be a gender effect as in $\mathrm{Cl}$ (predominantly female) "ashamed" scored highest of all items after MRT. Therefore, it is not yet clear whether our MRT is capable of specifically activating the intended emotions but also how strongly unequal gender distribution biased results of studies with predominantly female samples (e.g. Strohm et al., 2019: 81.5\% females, Siegesleitner et al., 2019: 100\% females; Çili et al., 2017: 95 $\%$ females). Unfortunately, we did not do sound recordings of the imagination and, therefore, are unable to ascertain if participants followed the audio instructions. The short form of the Traumatic 
Memory Inventory-Post-Script-Version (TMI-PS, Hopper et al., 2007) could be used for the assessment of intensities for different memory components.

In summary, our PTSD analogue design seems to be a useful tool to study effects of treatment elements on trauma-related emotions and other variables. Its advantages lie in the high standardization, easy application and replicability. In future, it could be useful as an online therapy tool e.g. as add-on for ongoing therapy or to bridge the waiting time for a treatment place. However, the nature of the study was highly preliminary because of the new method of presenting the MRT and the intervention techniques as well as the early stage in the development of the FESS. Due to shortcomings in the experimental and sampling procedure we cannot draw satisfactory conclusions about the differential effectiveness of our mini-interventions. In follow-up studies, we want to align the duration of the interventions and estimate effects compared to a no-intervention control group in a larger and more balanced sample. Furthermore, we consider measuring online physiological data to objectify selfreport assessments. 


\section{References}

Arnau, J., Bendayan, R., Blanca, M. J., \& Bono, R. (2013). The effect of skewness and kurtosis on the robustness of linear mixed models. Behavior Research Methods, 45(3), 873-879. https://doi.org/10.3758/s13428-012-0306-x

Arntz, A., Tiesema, M., \& Kindt, M. (2007). Treatment of ptsd: A comparison of imaginal exposure with and without imagery rescripting. Journal of Behavior Therapy and Experimental Psychiatry, 38(4), 345-370. https://doi.org/10.1016/j.jbtep.2007.10.006

Arntz, A., \& Weertman, A. (1999). Treatment of childhood memories: Theory and practice. Behaviour Research and Therapy, 37(8), 715-740. https://doi.org/10.1016/S0005-7967(98)00173-9

Au, T. M., Sauer-Zavala, S., King, M. W., Petrocchi, N., Barlow, D. H., \& Litz, B. T. (2017). Compassionbased therapy for trauma-related shame and posttraumatic stress: Initial evaluation using a multiple baseline design. Behavior Therapy, 48(2), 207-221. https://doi.org/10.1016/j.beth.2016.11.012

Badour, C. L., \& Feldner, M. T. (2018). The role of disgust in posttraumatic stress. Journal of Experimental Psychopathology, 9(3), 1-26. https://doi.org/10.5127/pr.032813

Bomyea, J., \& Allard, C. B. (2017). Trauma-related disgust in veterans with interpersonal trauma. Journal of Traumatic Stress, 30(2), 149-156. https://doi.org/10.1002/jts.22169

Bradley, R., Greene, J., Russ, E., Dutra, L., \& Westen, D. (2005). A multidimensional meta-analysis of psychotherapy for ptsd. American Journal of Psychiatry, 162, 214-227.

Breyer, B., \& Bluemke, M. (2016). Deutsche Version der Positive and Negative Affect Schedule (PANAS) [German version of the positive and negative affect schedule (PANAS)]. Zusammenstellung sozialwissenschaftlicher Items und Skalen (ZIS). GESIS Panel. https://doi.org/10.6102/zis242

Çili, S., Pettit, S., \& Stopa, L. (2017). Impact of imagery rescripting on adverse self-defining memories and post-recall working selves in a non-clinical sample: A pilot study. Cognitive Behaviour Therapy, 46(1), 75-89. https://doi.org/10.1080/16506073.2016.1212396 
Dibbets, P., \& Arntz, A. (2016). Imagery rescripting: Is incorporation of the most aversive scenes necessary? Memory, 24(5), 683-695. https://doi.org/10.1080/09658211.2015.1043307

Ehlers, A., \& Clark, D. M. (2000). A cognitive model of posttraumatic stress disorder. Behaviour Research and Therapy, 38, 319-345. https://doi.org/10.1016/s0005-7967(99)00123-0

Feiring, C., \& Taska, L. S. (2005). The persistence of shame following sexual abuse: A longitudinal look at risk and recovery. Child Maltreatment, 10(4), 337-349. https://doi.org/10.1177/1077559505276686

Foa, E. B., Hembree, E. A., \& Rothbaum, B. O. (2014). Handbuch der Prolongierten Exposition: Basiskonzepte und Anwendung. Eine Anleitung für Therapeuten [Prolonged Exposure Therapy for PTSD: Therapist Guide] (1st ed.). Probst.

Foa, E. B., \& Kozak, M. J. (1986). Emotional processing of fear: Exposure to corrective information. Psychological Bulletin, 99(1), 20-35. https://doi.org/10.1037/0033-2909.99.1.20

Freed, S., \& D'Andrea, W. (2015). Autonomic arousal and emotion in victims of interpersonal violence: Shame proneness but not anxiety predicts vagal tone. Journal of Trauma \& Dissociation : The Official Journal of the International Society for the Study of Dissociation (ISSD), 16(4), 367383. https://doi.org/10.1080/15299732.2015.1004771

Grunert, B. K., Weis, J. M., Smucker, M. R., \& Christianson, H. F. (2007). Imagery rescripting and reprocessing therapy after failed prolonged exposure for post-traumatic stress disorder following industrial injury. Journal of Behavior Therapy and Experimental Psychiatry, 38(4), 317-328. https://doi.org/10.1016/j.jbtep.2007.10.005

Hagenaars, M. A., \& Arntz, A. (2012). Reduced intrusion development after post-trauma imagery rescripting; an experimental study. Journal of Behavior Therapy and Experimental Psychiatry, 43(2), 808-814. https://doi.org/10.1016/j.jbtep.2011.09.005

Harned, M. S., Ruork, A. K., Liu, J., \& Tkachuck, M. A. (2015). Emotional activation and habituation during imaginal exposure for ptsd among women with borderline personality disorder. Journal of Traumatic Stress, 28(3), 253-257. https://doi.org/10.1002/jts.22013 
Holmes, E. A., \& Bourne, C. (2008). Inducing and modulating intrusive emotional memories: A review of the trauma film paradigm. Acta Psychologica, 127(3), 553-566.

https://doi.org/10.1016/j.actpsy.2007.11.002

Hopper, J. W., Frewen, P. A., Sack, M., Lanius, R. A., \& van der Kolk, B. A. (2007). The responses to script-driven imagery scale (rsdi): Assessment of state posttraumatic symptoms for psychobiological and treatment research. Journal of Psychopathology and Behavioral Assessment, 29(4), 249-268. https://doi.org/10.1007/s10862-007-9046-0

Kocherscheidt, K., Fiedler, P., Kronmüller, K.-T., Backenstraß, M., \& Mundt, C. (2002). Zur empirischen Unterscheidung von Scham und Schuld [On the empirical differentiation of shame and guilt]. Zeitschrift für Differentielle und Diagnostische Psychologie, 23(2), 217-224. https://doi.org/10.1024//0170-1789.23.2.217

Kubany, E. S., Haynes, S. N., Abueg, F. R., Manke, F. P., Brennan, J. M., \& Stahura, C. (1996). Development and validation of the trauma-related guilt inventory (trgi). Psychological Assessment, 8(4), 428-444. https://doi.org/10.1037/1040-3590.8.4.428

Kubany, E. S., \& Watson, S. B. (2003). Guilt: Elaboration of a multidimensional model. The Psychological Record, 53, 51-90.

Kulla, P., Grabow, J. M., Bleiziffer, U., Kratzer, L., \& Kruse, J. (2021). Fragebogen zu ereignisbezogenen Scham- und Schuldgefühlen: Ein reliables und valides Instrument für Forschung und Praxis [Poster] [Development and Initial Validation of the Event-Related Shame and Guilt Scale]. Würzburg. Deutschsprachige Gesellschaft für Psychotraumatologie.

Kunze, A. E., Arntz, A., \& Kindt, M. (2015). Fear conditioning with film clips: A complex associative learning paradigm. Journal of Behavior Therapy and Experimental Psychiatry, 47, 42-50. https://doi.org/10.1016/j.jbtep.2014.11.007

Kunze, A. E., Arntz, A., \& Kindt, M. (2019). Investigating the effects of imagery rescripting on emotional memory: A series of analogue studies. Journal of Experimental Psychopathology, 10(2), 204380871985073. https://doi.org/10.1177/2043808719850733 
Kunze, A. E., Arntz, A., Morina, N., Kindt, M., \& Lancee, J. (2017). Efficacy of imagery rescripting and imaginal exposure for nightmares: A randomized wait-list controlled trial. Behaviour Research and Therapy, 97, 14-25. https://doi.org/10.1016/j.brat.2017.06.005

Lakens, D. (2013). Calculating and reporting effect sizes to facilitate cumulative science: A practical primer for t-tests and anovas. Frontiers in Psychology, 4, 863.

https://doi.org/10.3389/fpsyg.2013.00863

Langkaas, T. F., Hoffart, A., Øktedalen, T., Ulvenes, P. G., Hembree, E. A., \& Smucker, M. (2017). Exposure and non-fear emotions: A randomized controlled study of exposure-based and rescripting-based imagery in ptsd treatment. Behaviour Research and Therapy, 97, 33-42. https://doi.org/10.1016/j.brat.2017.06.007

Lewis, C., Roberts, N. P., Andrew, M., Starling, E., \& Bisson, J. I. (2020). Psychological therapies for post-traumatic stress disorder in adults: Systematic review and meta-analysis. European Journal of Psychotraumatology, 11(1), 1729633. https://doi.org/10.1080/20008198.2020.1729633

Lewis, C., Roberts, N. P., Gibson, S., \& Bisson, J. I. (2020). Dropout from psychological therapies for post-traumatic stress disorder (ptsd) in adults: Systematic review and meta-analysis. European Journal of Psychotraumatology, 11(1), 1709709. https://doi.org/10.1080/20008198.2019.1709709

Lewis, H. B. (1971). Shame and Guilt in Neurosis (1st ed.). International Universities Press.

Maercker, A., \& Schützwohl, M. (1998). Erfassung von psychischen Belastungsfolgen: Die Impact of Event Skala-revidierte Version [Assessing the psychological impact of distressing events: The Impact of Event Scale - revised]. Diagnostica, 44, 130-141. https://doi.org/10.1037/t55092-000

Morris, S. B., \& DeShon, R. P. (2002). Combining effect size estimates in meta-analysis with repeated measures and independent-groups designs. Psychological Methods, 7(1), 105-125. https://doi.org/10.1037//1082-989X.7.1.105

Neufeld, S. A. S., Sikkema, K. J., Lee, R. S., Kochman, A., \& Hansen, N. B. (2012). The development and psychometric properties of the hiv and abuse related shame inventory (harsi). AIDS and Behavior, 16(4), 1063-1074. https://doi.org/10.1007/s10461-011-0086-9 
$\varnothing$ ktedalen, T., Hagtvet, K. A., Hoffart, A., Langkaas, T. F., \& Smucker, M. (2014). The trauma related shame inventory: Measuring trauma-related shame among patients with ptsd. Journal of Psychopathology and Behavioral Assessment, 36(4), 600-615. https://doi.org/10.1007/s10862014-9422-5

$\varnothing$ ktedalen, T., Hoffart, A., \& Langkaas, T. F. (2015). Trauma-related shame and guilt as time-varying predictors of posttraumatic stress disorder symptoms during imagery exposure and imagery rescripting--a randomized controlled trial. Psychotherapy Research : Journal of the Society for Psychotherapy Research, 25(5), 518-532. https://doi.org/10.1080/10503307.2014.917217

Pugh, L. R., Taylor, P. J., \& Berry, K. (2015). The role of guilt in the development of post-traumatic stress disorder: A systematic review. Journal of Affective Disorders, 182, 138-150. https://doi.org/10.1016/j.jad.2015.04.026

Saraiya, T., \& Lopez-Castro, T. (2016). Ashamed and afraid: A scoping review of the role of shame in post-traumatic stress disorder (ptsd). Journal of Clinical Medicine, 5(11). https://doi.org/10.3390/jcm5110094

Schmucker, M., \& Köster, R. (2017). Praxishandbuch IRRT: Imagery Rescripting \& Reprocessing Therapy bei Traumafolgestörungen, Angst, Depression und Trauer [Imagery Rescripting \& Reprocessing Therapy for trauma-related disorders, anxiety, depression, and grief] (3rd ed.). Leben Lernen. Klett-Cotta.

Siegesleitner, M., Strohm, M., Wittekind, C. E., Ehring, T., \& Kunze, A. E. (2019). Effects of imagery rescripting on consolidated memories of an aversive film. Journal of Behavior Therapy and Experimental Psychiatry, 62, 22-29. https://doi.org/10.1016/j.jbtep.2018.08.007

Strohm, M., Siegesleitner, M., Kunze, A. E., Ehring, T., \& Wittekind, C. E. (2019). Imagery rescripting of aversive autobiographical memories: Effects on memory distress, emotions, and feelings of mastery. Cognitive Therapy and Research, 43(6), 1005-1017. https://doi.org/10.1007/s10608019-10021-2 
Waters, A. M., LeBeau, R. T., \& Craske, M. G. (2017). Experimental psychopathology and clinical psychology: An integrative model to guide clinical science and practice. Psychopathology Review, 4(2), 112-128. https://doi.org/10.5127/pr.038015

Watkins, L. E., Sprang, K. R., \& Rothbaum, B. O. (2018). Treating ptsd: A review of evidence-based psychotherapy interventions. Frontiers in Behavioral Neuroscience, 12, 258.

https://doi.org/10.3389/fnbeh.2018.00258

Watson, D., Clark, L. A., \& Tellegen, A. (1988). Development and validation of brief measures of positive and negative affect: the panas scales. Journal of Personality and Social Psychology, 54(6), 1063-1070. https://doi.org/10.1037/0022-3514.54.6.1063

Weiss, D. S., \& Marmar, C. R. (1996). Impact of event scale - revised. In Wilson, J. P., Keane, T. M. (Ed.), Assessing psychological trauma and ptsd. Guilford. 